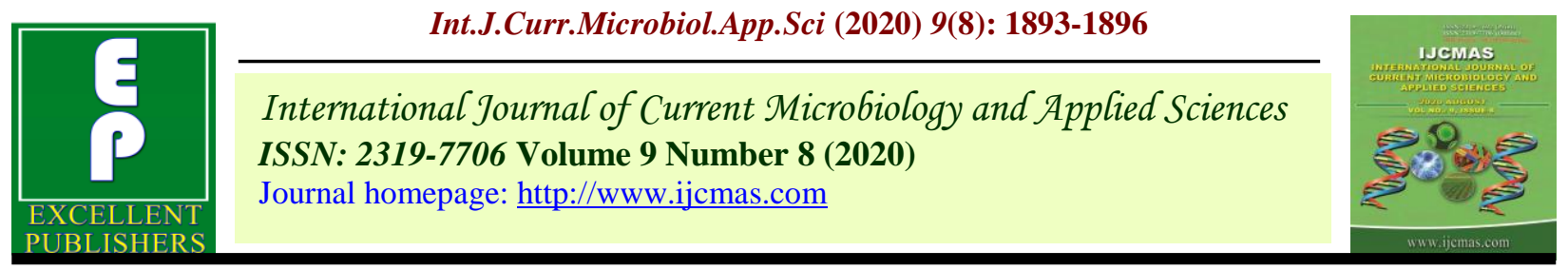

Original Research Article

https://doi.org/10.20546/ijcmas.2020.908.216

\title{
Fertility and Hatchability of Indigenous Siruvidai Chicken of Tamil Nadu
}

\author{
J. Jamima, R. Richard Churchil* and G. Srinivasan \\ Department of Poultry Science, Madras Veterinary College, Tamil Nadu Veterinary and \\ Animal Sciences University, Chennai -7, India \\ *Corresponding author
}

\begin{tabular}{|l|}
\hline Ke y w o r d s \\
Fertility, \\
Hatchability, \\
Siruvidai, \\
Chicken
\end{tabular}

\section{A B S T R A C T}

Siruvidai and Peruvidai chicken are the major indigenous chicken ecotypes of Tamil Nadu state, India. A study was conducted to assess the fertility and hatchability of Siruvidai chicken hatching eggs incubated in a homestead incubator. The fertility, hatchability and embryonic mortality were recorded. The eggs failed to hatch out were break opened to determine the stage of embryonic mortality. The average fertility rate ranged from 85.00 to $91.67 \%$ in different hatches with the average value of $88.41 \%$. The hatchability on total egg set ranged from 81.71 to $85.87 \%$ and the overall mean was 84.19 ; whereas the hatchability on fertile egg set ranged between 92.73 and 98.75 with the mean value of $95.28 \%$. The breakopen study of unhatched eggs revealed $2.57 \%$ early embryonic mortality (range: $1.25-3.64 \%$ ), $0.84 \%$ mid embryonic mortality (range: 0.00 to $1.82 \%$ ) and $1.31 \%$ of late embryonic mortality including dead in shell (range: 0.00 to $2.11 \%$ ). The total embryonic mortality was $4.72 \%$ with the values ranging from 1.25 to $7.27 \%$. The results indicated good reproductive performance of indigenous Siruvidai chicken and efficient hatching of its eggs when homestead incubator is used.

\section{Introduction}

The smallholder chicken sector is traditionally based on extensive production systems where the birds find most of their feed through scavenging. The twentieth livestock census results (DAHD, 2019) indicates that the total Poultry in the country is 851.81 Million in 2019 , with the increase of $16.8 \%$ over previous census (729.2 Million in 2012); whereas, the total backyard poultry in the country was 317.07 Million in 2019, increasing $45.8 \%$ over previous census. Indigenous chicken contributes to more than $20 \%$ of total egg production in India. These birds are also known for their adaptive superiority in terms of their resistance to endemic diseases and other harsh environmental conditions (Nwakpu et al., 1999). Therefore more attention should be given to study and characterize the lesser known and largely neglected ecotypes/ breeds like Siruvidai chicken so as to plan for conservation and posterity. This non-descript 
ecotype of Tamil Nadu state of India gained a lot of interest in the recent years and small scale farmers involved in breeding of this germplasm is increasing. However the detailed characterization of this chicken with respect to its egg and hatchability traits is generally unavailable. This information must necessarily precede their genetic improvement for commercial traits. The objective of the present work is to characterize the Siruvidai chicken for hatchability performance.

\section{Materials and Methods}

A study was conducted to evaluate the fertility, hatchability and embryonic mortality pattern in indigenous Siruvidai chicken of Tamil Nadu. The study was conducted in Thanjavur district, Tamil Nadu, India. The eggs used for this study was collected from Siruvidai hens reared under backyard system of management in a farm for the last 6 years from generation to generation. The base population of these birds was originally collected from local farmers from the breeding tracts in the surrounding area. The sex ratio practiced in the farm was 1:5. The eggs were collected and stored at room temperature and set in a small homestead automatic setter cum hatcher with total setting capacity of 1000 eggs. The temperature was maintained at $100^{\circ} \mathrm{F}$ and relative humidity at $65 \%$. The eggs were set at weekly interval. The eggs set were turned at hourly interval during first 18 days of incubation. On completion of 18 days of incubation in setter trays, the eggs were transferred to hatcher trays and placed horizontally to continue the incubation. The hatched out chicks were pulled on $21^{\text {st }}$ day. The unhatched eggs were break-opened to examine the cause for the failure of hatching. From the breakopen study, number of infertile egg, embryonic mortality at early ( 0 - 7 days $)$, mid (8 - 14 days) and late (15 -21 days) periods of incubation were recorded. The data was entered in Microsoft Excel worksheet and the average values of fertility, hatchability on total egg set, hatchability on fertile egg set, embryonic mortality during early, mid and late incubation periods were calculated.

\section{Results and Discussion}

The incubation results and the findings of breakopen studies of unhatched eggs of indigenous Siruvidai chicken is presented in Table 1.

A total of 376 indigenous Siruvidai eggs were incubated in three hatches of 164, 120 and 92 eggs. Among 376 eggs 332 eggs were fertile. The fertility values in individual hatches varied from 86.59 to $91.67 \%$ with mean value of $88.41 \%$. This is in close agreement with the earlier reports on indigenous chicken of India (90.40\%; Islam et al., 2014) and Uganda (91.6\%; Trail, 1962). The results indicated that the fertility was comparatively better in Siruvidai chicken than that of previously reported values of $76.33 \%$ in indigenous chicken of Assam (Kalita et al., 2012), $79.55 \%$ in Tellicherry chicken of Kerala state in India (Kumar et al., 2013) and $70.81 \%$ in indigenous chicken of Bangladesh (Desha et al., 2015).

Out of 376 eggs set, 315 eggs hatched out. The hatchability (\%) value on total egg set ranged from 85.00 to $85.87 \%$ in different hatches with overall mean of $84.19 \%$. The overall hatchability on total egg set observed in this study was higher than the earlier report of $67.05 \%$ in Tellicherry breed of chicken (Kumar et al., 2013). A closer value of $87.52 \%$ has been reported in indigenous birds of Assam (Islam et al., 2014). However, a very low value of 41.36 and 58.75 hatchability (\%) on total egg set were recorded in indigenous (Kalita et al., 2012) and crossbred with indigenous (Kalita et al., 2013) birds. The hatchability of eggs from the fertile eggs set in different hatches in this 
study ranged from 92.73 to $98.75 \%$, with overall value of $95.28 \%$. On perusal of literature, the hatchability on fertile egg set observed in this study was higher compared to that $83.4 \%$ in European breeds of Uganda (Trail, 1962) and 84.29\% in Tellicherry breed of Kerala, India (Kumar et al., 2013).

The eggs failed to hatch $(n=61)$ were breakopened to identify the cause of non-hatching. A total of 44 eggs were found infertile. The hatchwise fertility rate $(\%)$ revealed an overall value of 88.41 with values ranging from 86.59 to 91.67 in different hatches. The overall hatches calculated on fertile egg set (\%) was 95.28 with values ranging from 92.73 to 98.75 in different hatches. higher compare to embryonic mortality during mid $(0.84 \%)$ and late $(1.31 \%)$ periods. The total embryonic mortality was $4.2 \%$. The total embryonic mortality observed in this study was comparable to that of Tellicherry chicken in natural incubation (14.95\%) and artificial incubation (15.72\%) as reported by Kumar et al., (2013).

However, the embryonic mortality pattern was different with high incidence during early embryonic life $(7.71 \%)$ in this study compare to $3.13 \%$ in earlier report (Kumar et al., 2013). The late embryonic mortality also showed a reverse pattern of low incidence of $3.93 \%$ in this study compare to $8.39 \%$ in earlier report (Kumar et al., 2013).

The early embryonic mortality $(2.57 \%)$ was

Table.1 The fertility, hatchability and embryonic mortality parameters of indigenous Siruvidai chicken

\begin{tabular}{|c|c|c|c|c|c|c|c|c|}
\hline $\begin{array}{c}\text { Hatch } \\
\text { No }\end{array}$ & $\begin{array}{c}\text { No of } \\
\text { eggs }\end{array}$ & $\begin{array}{c}\text { Fertility } \\
(\mathbf{\%})\end{array}$ & $\begin{array}{c}\text { Hatchability } \\
\text { TES }(\mathbf{\%})\end{array}$ & $\begin{array}{c}\text { Hatchability } \\
\text { FES }(\mathbf{\%})\end{array}$ & \multicolumn{4}{|c|}{ Embryonic mortality (\%) } \\
\hline & & & & & $\begin{array}{c}\text { Early } \\
(<7 \\
\text { days })\end{array}$ & $\begin{array}{c}\text { Mid } \\
(\mathbf{8}-\mathbf{1 4} \\
\text { days })\end{array}$ & $\begin{array}{c}\text { Late } \\
(\mathbf{1 5}-\mathbf{2 1} \\
\text { days })\end{array}$ & $\mathbf{T}$ \\
\hline $\mathbf{1}$ & 164 & 86.59 & 81.71 & 94.37 & 2.82 & 0.7 & 2.11 & 5.63 \\
\hline $\mathbf{2}$ & 120 & 91.67 & 85 & 92.73 & 3.64 & 1.82 & 1.82 & 7.27 \\
\hline $\mathbf{3}$ & 92 & 86.96 & 85.87 & 98.75 & 1.25 & 0 & 0 & 1.25 \\
\hline Overall & $\mathbf{3 7 6}$ & $\mathbf{8 8 . 4 1}$ & $\mathbf{8 4 . 1 9}$ & $\mathbf{9 5 . 2 8}$ & $\mathbf{2 . 5 7}$ & $\mathbf{0 . 8 4}$ & $\mathbf{1 . 3 1}$ & $\mathbf{4 . 7 2}$ \\
\hline
\end{tabular}

It is concluded from this study that indigenous Siruvidai chicken of Tamil Nadu possess good reproductive traits as indicated by good fertility and hatchability compared to other similar indigenous chicken populations. Although, the Siruvidai chickens are known for their mothering ability and broodiness, the eggs hatch well when incubated by artificial incubation in small homestead incubators.

\section{References}

DAHD (2019). Provisional key results of $20^{\text {th }}$ livestock census. Department of Animal
Husbandry and Dairying, Ministry of Fisheries, Animal Husbandry \& Dairying, Government of India, Retrieved from http://dahd.nic.in/division/provisionalkey-results-20th-livestock-census (Accessed on 28-03-2020).

Desha, N.H., Islam, F., Ibrahim, M.N.M., Okeyo, M., Jianlin, H. and ABhuiyan, K.F.H. 2015. Fertility and hatchability of eggs and growth performance of mini-incubator hatched indigenous chicken in rural areas of Bangladesh, Tropical Agricultural Research Vol. 26 
(3): $528-536$

Islam. R., N. Kalita and P. Nath. 2014. Comparative performance of Vanaraja and Indigenous chicken under backyard system of rearing. Journal of Poultry Science and Technology, 2 (1): 22-25

Kalita N., N. Pathak and R. Islam. 2012. Performance of Indigenous chicken in intensive system of management. Indian Veterinary Journal, 89: 43-44.

Kalita. N., N. Pathak, M. Ahmed and G. K. Saikia. 2013. Various causes related to dead-in-shell embryos of crossbred (PB$2 \mathrm{x}$ Indigenous) chicken egg. Veterinary World, 6:774 - 777

Kumar. P. G., R. R. Churchil, A. Jalaludeen, K. Narayanankutty and A. Kannan.
2013. Egg quality and hatchability characters of Tellicherry chicken reared under extensive system of management. Indian Journal of Poultry Science, 48(2): 265-268.

Nwakpu. P. E, B. I, Odo, S. I. Omeje, M. Akpa and C. C. Edoga. 1999. Hatching performance of three strains of layertype chicken and their lines. Proceedings of the $26^{\text {th }}$ Annual Conference, NSAP, 21-25 March, Ilorin.

Trail. J. C. M. 1962. The Fertility, Hatchability and Chick mortality compared with European Breeds. Poultry Science, 41 (1): 1271 - 1276.

\section{How to cite this article:}

Jamima, J., R. Richard Churchil and Srinivasan, G. 2020. Fertility and Hatchability of Indigenous Siruvidai Chicken of Tamil Nadu. Int.J.Curr.Microbiol.App.Sci. 9(08): 1893-1896. doi: https://doi.org/10.20546/ijcmas.2020.908.216 